OPEN ACCESS

Edited by:

Eugenia Bezirtzoglou,

Democritus University of Thrace,

Greece

Reviewed by:

XueWei Xu,

Ministry of Natural Resources, China

Konstantinos Papadimitriou,

University of Peloponnese, Greece

*Correspondence.

Joseph Wambui

joseph.wambui@uzh.ch

Specialty section:

This article was submitted to

Food Microbiology,

a section of the journal

Frontiers in Microbiology

Received: 22 April 2020 Accepted: 04 August 2020

Published: 24 August 2020

Citation

Wambui J, Cernela N, Corti S and Stephan R (2020) Comparative

Genome Analysis and Phenotypic

Characterization of Clostridium gasigenes CGASO01 Isolated From Chilled Vacuum-Packed Lamb Meat.

Front. Microbiol. 11:2048.

doi: 10.3389/fmicb.2020.02048

\section{Comparative Genome Analysis and Phenotypic Characterization of Clostridium gasigenes CGAS001 Isolated From Chilled Vacuum-Packed Lamb Meat}

\author{
Joseph Wambui*, Nicole Cernela, Sabrina Corti and Roger Stephan \\ Institute for Food Safety and Hygiene, Vetsuisse Faculty, University of Zurich, Zurich, Switzerland
}

Genomic data for psychrophilic bacteria causing blown pack spoilage (BPS) are limited. This study characterizes the genome of a novel Clostridium gasigenes strain CGAS001 isolated from meat juice sample (MJS) of vacuum-packed lamb meat by comparing it with the type strain C. gasigenes DSM 12272 and five strains representing four other BPS-causing Clostridium sensu stricto species. Phenotypic characteristics of the strain, which include biochemical characteristics, antimicrobial resistance and production of putative polyketide, have been determined. The size of its draft genome is $4.1 \mathrm{Mb}$ with 3,845 coding sequences, $28.7 \%$ GC content and 95 RNA genes that include 75 tRNAs, 17 rRNAs, and 3 ncRNAs. Average Nucleotide Identity (ANI) and digital DNA-DNA Hybridization (dDDH) predict that C. gasigenes CGAS001 and DSM 12272 constitute a single species (ANI and dDDH $=98.3 \%$ for speciation) but two distinct subspecies ( $\mathrm{dDDH}=73.3 \%$ for subspeciation). The genome is characterized by saccharolytic, lipolytic and proteolytic genes as well as hemolysins and phospholipases, which are consistent with its phenotype. The genome also reveals the ability of $C$. gasigenes to synthesize polyketides which is demonstrated by the antimicrobial activity of a crude polyketide extract against Listeria monocytogenes and Enterococcus devriesei. The strain is resistant to polymyxin B and streptomycin. The genetic and phenotypic analyses suggest that CGAS001 constitutes a novel subspecies of $C$. gasigenes adapted to a saprophytic lifestyle and can synthesize narrow spectrum antimicrobial compounds.

Keywords: Clostridium gasigenes, blown pack spoilage, chilled meat, genome analysis, antibiotic resistance, toxins, polyketides

\section{INTRODUCTION}

Clostridium gasigenes is a psychrophilic anaerobic Gram-stain-positive bacterium and a member of Clostridium sensu stricto, which causes a type of meat spoilage commonly referred to as blown pack spoilage (BPS) (Broda et al., 2000). The spoilage is characterized by gas production and pack distention usually occurring without pack integrity or temperature abuse (Wambui and Stephan, 2019). Since the first confirmed case of BPS caused by C. gasigenes in New Zealand (Broda et al., 2000), the species has been detected and/or isolated from BPS in other countries including Ireland (Moschonas et al., 2009; Bolton et al., 2015) and Brazil (Silva et al., 2011). 
C. gasigenes is, together with Clostridium estertheticum, one of the main causes for BPS in vacuum packed and refrigerated meat (Reid et al., 2017; Dorn-In et al., 2018). Other causative agents include Clostridium algidicarnis, Clostridium frigidicarnis, and Clostridium tagluense (Adam et al., 2010; Cavill et al., 2011).

As a strict anaerobe, C. gasigenes would not persist on meat surfaces in aerobic conditions in the vegetative state, hence it is likely its spores are the major contaminants of meat within the slaughterhouses. Within these premises, the main reservoirs for C. gasigenes have been suggested to include soil, hides and feces (Broda et al., 2002, 2009). Upon contamination, vacuum packing and cold storage then provide conditions that are necessary for spore germination and finally BPS (Wambui and Stephan, 2019). Ten spores of $C$. gasigenes seem to be enough to cause BPS in vacuum packed meat (Moschonas et al., 2010), with the BPS occurring within 36 days or 56 days at $1^{\circ} \mathrm{C}$ depending on applied meat processing techniques (Moschonas et al., 2011b). The spores are therefore a primary target for reducing the occurrence of BPS (Moschonas and Bolton, 2013). Data have shown, that oxygen exposure is a possible option to prevent growth of germinated C. gasigenes spores (Adam et al., 2013). Besides this, no other data are available in regards to $C$. gasigenes spore characteristics, including resistance mechanisms or germinants (Adam et al., 2010).

The exact mechanisms by which $C$. gasigenes and the other psychrophilic anaerobic Clostridium spp. cause BPS remain largely unknown (Húngaro et al., 2016). However, it has been suggested that lactate utilization is important for BPS inception especially by C. estertheticum (Yang et al., 2010). Lactate is also a germinant for C. estertheticum spores (Rajagopal et al., 2016). On the other hand, C. gasigenes does not utilize lactate (Yang and Badoni, 2013), instead, lactate is one of its metabolites (Broda et al., 2000). Therefore, there exist metabolic processes and possibly spore germination mechanisms that are fundamentally different between C. gasigenes and C. estertheticum through which they cause BPS. Further studies on how psychrophilic clostridia cause BPS, including the identification of functional genes, have been suggested (Adam et al., 2010; Yang et al., 2014).

Up to now, BPS data is limited to phenotypic studies. In the current genomic era, it is imperative that phenotypic BPS studies are supplemented by genomic-based studies. Universal systems for gene knockout, including ClosTron (Heap et al., 2007) and RiboCas (Cañadas et al., 2019) that allow effective exploitation of Clostridial genome data have already been developed. Utilization of these systems can unravel the missing information regarding metabolic processes, spore characteristics and other features that are vital for BPS prevention. Other unknown characteristics including toxins and antimicrobial compounds such as those encoded in the genome of C. estertheticum (Yu et al., 2016) can be identified and studied. Beyond BPS and the public safety concerns, genome data can unravel new class of compounds including antimicrobials that have therapeutic use. Presently, only a few of these compounds have been reported for Clostridium spp. (Pahalagedara et al., 2020). There is therefore a need for amassing and mining genome data for the unexploited psychrophilic Clostridium species.

In this study, the whole genome sequence of C. gasigenes strain CGAS001, isolated from vacuum packed lamb meat, was characterized. Including the genomes of the type strains C. gasigenes DSM 12272 (Broda et al., 2000) and five selected strains representing four other BPS-causing Clostridium sensu stricto species, provided an excellent opportunity for the first comprehensive comparative analysis involving psychrophilic anaerobic Clostridium spp. causing BPS. Valuable insights into the lifestyle, metabolic diversity, public health significance and secondary metabolites of the strain have been uncovered.

\section{MATERIALS AND METHODS}

\section{Bacterial Isolation and Culturing}

Ten meat juice samples (MJS) from a recent study (Wambui et al., 2020) were investigated. The MJS were positive for anaerobic psychrophilic Clostridium spp. after an initial real-time PCR (RTPCR) screening. Isolation was carried out anaerobically in a multi-step approach involving spores recovery and elimination of competitive microflora by heat or ethanol treatment followed by enrichment and plating as previously described (Moschonas et al., 2009). Briefly, $1 \mathrm{ml}$ of each positive MJS was mixed with $9 \mathrm{ml}$ pre-reduced peptone-yeast-glucose-starch (PYGS) medium (Broda et al., 2000) and divided into two. One set was heated at $80^{\circ} \mathrm{C}$ for $10 \mathrm{~min}$ while the other set was mixed with $50 \%$ ethanol $(\mathrm{v} / \mathrm{v})$ for $1 \mathrm{~h}$ at $4^{\circ} \mathrm{C}$. Both sets were incubated anaerobically for 3 weeks at $4^{\circ} \mathrm{C}$ after which, they were serially diluted and plated on Columbia Agar supplemented with 5\% defibrinated sheep blood (CBA). The plates were incubated anaerobically for 3 weeks at $4^{\circ} \mathrm{C}$. Colonies with previously described characteristics (Moschonas et al., 2009) were selected and purified for 2 weeks at $4^{\circ} \mathrm{C}$. Representative colonies were gram stained and screened by RT-PCR using the primers for psychrophilic Clostridium spp. (Brightwell and Clemens, 2012). One isolate from ethanol treated regime, whose cells appeared as long thick rods with or without spores and stained blue and genomic DNA was positive for psychrophilic Clostridium spp., was selected for whole genome sequencing.

\section{Genome Sequencing, Analysis, Assembly and Annotation}

DNA was isolated from a culture grown anaerobically for 10 days at $4^{\circ} \mathrm{C}$ on CBA using the DNeasy Blood and Tissue Kit (Qiagen, Hilden, Germany) and eluted in $10 \mathrm{mM}$ Tris $\mathrm{pH}$ 7.3. The DNA concentration was measured with a Nanodrop (Witec AG, Switzerland). Sequencing libraries were prepared using the Illumina Nextera DNA Flex and sequenced on an Illumina MiniSeq (Illumina, San Diego, CA, United States) with a minimal coverage of $50 \times$. The length of the library was 150-300 bp. After quality control with FastQC ${ }^{1}$, the reads were assembled with SPAdes v. 3.12.0. The quality of the genome was further determined in silico using CheckM v.1.018 (Parks et al., 2015) and Contest16S (Lee et al., 2017). The genome was annotated online in RAST $^{2}$ (Brettin et al., 2015) and NCBI Prokaryotic Genome Annotation Pipeline (Tatusova et al., 2016).

\footnotetext{
${ }^{1}$ http://www.bioinformatics.babraham.ac.uk/projects/fastqc/

${ }^{2}$ https://rast.nmpdr.org/rast.cgi
} 


\section{Strain Identification}

The identification of the strain was initially performed by the 16S rRNA gene using the EzBioCloud ${ }^{3}$ web server (Yoon et al., 2017a). Phylogenetic analyses were further carried out by comparing the 16S rRNA gene of the isolate with the $16 \mathrm{~S}$ rRNA gene sequences of other Clostridium sensu stricto spp. strains known to cause BPS namely; C. gasigenes DSM 12272, C. algidicarnis NCFB 2931, C. bowmanii DSM 14206, C. estertheticum DSM 8809, C. frigidicarnis SPL77A, C. frigoris DSM 14204, C. frigorophilum 14F, and C. tagluense A121. The $16 \mathrm{~S}$ rRNA sequences were aligned using the progressive alignment algorithm and a phylogenetic tree created from the aligned sequences in CLC Workbench Genomics v. 8.1 (Qiagen, Aarhus, Denmark) using the neighborhood joining tree construction method while applying the Jukes-Cantor nucleotide substitution model. Bootstraps were based on 1,000 replicates with other parameters set to default. The sequences were downloaded from the National Center for Biotechnology Information (NCBI) database $^{4}$ (NCBI Resource Coordinators, 2018).

The delimitation of the isolate by its whole genome sequence (WGS) was carried out in silico through digital DNA-DNA hybridization (dDDH) using DMSZ's Genome-to-Genome Distance Calculator ${ }^{5}$ web server (Meier-Kolthoff et al., 2013) against WGS of C. gasigenes DSM 12272 (Genbank GCA_900104115.1) and five strains from four BPS-causing clostridia sensu stricto. Three species were represented by one strain each namely, C. algidicarnis B3 (Genbank; GCA_000703125.1), C. frigidicarnis DSM 12271 (Genbank; GCA_900111985.1) and C. tagluense A121 (Genbank; GCA_003865095.1) while C. estertheticum was represented by two strains; C. estertheticum subsp. estertheticum DSM 8809 (Genbank; GCA_001877035.1) and C. estertheticum subsp. laramiense DSM 14864 (Genbank; GCA_008933175.1). The WGS of the strains were downloaded from the NCBI database (NCBI Resource Coordinators, 2018). Furthermore, the Average Nucleotide Identity (ANI) of the isolate's WGS was compared against the WGS of the same clostridia strains using EzBioCloud ${ }^{6}$ web server (Yoon et al., 2017b). The genome of the isolate was also compared to and visualized against the genomes of C. gasigenes DSM 12272, C. algidicarnis B3, C. frigidicarnis DSM 12271, and C. estertheticum subsp. estertheticum DSM 8809 using BLAST Ring Image Generator (BRIG) software v. 0.95 (Alikhan et al., 2011).

\section{Gene Identification}

Virulence factors of the isolate were identified using VFDB $2019^{7}$ web server (Liu et al., 2019). PlasmidFinder v. $2.1^{8}$ and ResFinder v. $2.1^{9}$ (Zankari et al., 2012) servers was used to identify genes linked to plasmids and antimicrobial resistance, respectively. The

\footnotetext{
${ }^{3}$ https://www.ezbiocloud.net/

${ }^{4}$ https://www.ncbi.nlm.nih.gov/

${ }^{5}$ https://ggdc.dsmz.de/ggdc.php\#

${ }^{6} \mathrm{http}: / /$ www.ezbiocloud.net/tools/ani

${ }^{7}$ http://www.mgc.ac.cn/cgi-bin/VFs/v5/main.cgi?func=VFanalyzer

${ }^{8}$ https://cge.cbs.dtu.dk/services/PlasmidFinder/

${ }^{9}$ https://cgE.cbs.dtu.dk/services/ResFinder/
}

pathogenicity potential of the strain in humans was determined using PathogenFinder v. $1.1^{10}$ web server (Cosentino et al., 2013). Blast search analyses were performed for unique gene sequences using NCBI Blast server ${ }^{11}$ while the domains and topography of unique proteins encoded by the genes were predicted using NCBI Conserved Domain Database ${ }^{12}$ (Marchler-Bauer et al., 2009) and Phobius ${ }^{13}$ web servers, respectively. Detailed identification of metabolic genetic elements, other genes/proteins of interest and the comparison of these components with BPS causing Clostridium spp. strains was carried out in RAST (Brettin et al., 2015).

\section{Genome Comparison and Interpretation of Data From RAST}

A one versus all genomes comparison strategy was carried out in RAST (Brettin et al., 2015). The full list of annotated coding sequences (CDS) using RAST for both C. gasigenes strains CGAS001 (strain identified in this study) and DSM 12,272 (type strain) were summarized in two Excel files. First, only the sequences of both CGAS001 and DSM 12272 (Supplementary Tables S1, S2, respectively) were compared and presented with either strain serving as the reference strain and the other as the test strain. The output data included columns for contig number (Contig), gene number (Gene), gene identity (Gene ID), amino acid length of encoded protein (Length) and gene function (Function) for both strains. Additionally, a column for a homologous gene's percent identity (Percent ID) to a reference strain's gene was included. Lastly, CGAS001, as a reference strain, was compared with the five strains from four Clostridium spp. causing BPS mentioned above (Supplementary Table S3). The output data comprised of contig number (Contig), gene number (Gene), gene identity (Gene ID), amino acid length of encoded protein (Length) and gene function (Function) only for the reference strain. Only percent identity (Percent ID) of homologous genes to the reference strain's genes was included for the test strains. Reverse comparison for each of the Clostridium spp. test strain with CGAS001 was carried out individually (data no shown). In all outputs, CDS locus was based on the RAST annotation and are continuously referenced in this manuscript using the following example: CGAS001 peg.1 and DSM 12272 peg.10 referring to CDS loci 1 and 10 in strains CGAS001 and DSM 12272, respectively.

\section{Biochemical Characterization of Clostridium gasigenes CGAS001}

For biochemical characterization, cultures of CGAS001, grown on $\mathrm{CBA}$ for $72 \mathrm{~h}$ at $22^{\circ} \mathrm{C}$, were standardized to 3.0 MacFarland, inoculated in respective media and incubated anaerobically at $22^{\circ} \mathrm{C}$ for $5-7$ days. Saccharolytic and proteolytic assays were carried out on PYGS agar (PYGS medium with 1.5\% agar) and Nutrient agar with $2 \%$ Skim milk, respectively. Lipolytic and lecithinase activities were determined on

\footnotetext{
${ }^{10}$ https://cge.cbs.dtu.dk/services/PathogenFinder/

${ }^{11}$ https://blast.ncbi.nlm.nih.gov/Blast.cgi

${ }^{12}$ https://www.ncbi.nlm.nih.gov/Structure/cdd/wrpsb.cgi

${ }^{13}$ http://phobius.sbc.su.se/
} 
PYGS agar supplemented with $1 \%$ egg-yolk emulsion. For further biochemical profile characterization and acidification potential, API20A kit (bioMeriéux, Marcy l'Etoile, France) was used following manufacturer's specifications. All reagents in this section and subsequent sections were purchased from Sigma-Aldrich Chemie GmbH, Buchs, Switzerland, unless stated otherwise. All experiments were carried out in three biological replicates.

\section{Antibiotic Resistance Profile of Clostridium gasigenes CGAS001}

For antimicrobial resistance testing, an inoculum prepared as described above was spread with a sterile swab stick on Brucella Blood Agar. The testing was carried out by disk diffusion method against eight antibiotics; tetracycline $(30 \mu \mathrm{g})$, chloramphenicol $(30 \mu \mathrm{g})$, polymyxin B (300 $\mu \mathrm{g})$, streptomycin $(10 \mu \mathrm{g})$, clindamycin $(2 \mu \mathrm{g})$, erythromycin $(15 \mu \mathrm{g})$, penicillin (10 U), and vancomycin (30 $\mu \mathrm{g})$. The antibiotic disks were purchased from Becton Dickinson AG, Allschwil, Switzerland. Zones of inhibition were measured to nearest $\mathrm{mm}$. The antibiotic resistance tests were carried as per EUCAST guidelines for hemolytic bacteria and interpreted using the EUCAST guidelines for when standards are unavailable for a species ${ }^{14}$, which is the case for C. gasigenes. All experiments were carried out in three biological replicates.

\section{Screening of Clostridium gasigenes CGAS001 for Antimicrobial Activity}

The antimicrobial potential of CGAS001 was determined using the agar streak method (Almalki, 2020) with modifications. Briefly, a fresh culture of CGAS001 prepared as described above was streaked on CBA plates and incubated anaerobically for $72 \mathrm{~h}$ at $22^{\circ} \mathrm{C}$. Strains to be tested, L. monocytogenes EGDe (Glaser et al., 2001) and Escherichia coli grown aerobically on Brain Heart Infusion (BHI) agar and Luria-Bertani (LB) agar, respectively, for $24 \mathrm{~h}$ at $37^{\circ} \mathrm{C}$ were standardized to $0.5 \mathrm{McF}$ arland and streaked perpendicular to CGAS001 on the CBA plates. The plates were incubated aerobically at $37^{\circ} \mathrm{C}$ for $24 \mathrm{~h}$. Antimicrobial activity was determined as lack of growth by L. monocytogenes and E. coli near the streaked line of CGAS001. Where growth was absent, the zone of inhibition was measured to the nearest mm. All experiments were carried out in three biological replicates.

\section{Extraction and Characterization of Putative Polyketide From Clostridium gasigenes CGAS001 \\ Extraction of Putative Polyketide}

The extraction of crude polyketide was carried out by the solid agar method (Arasu et al., 2008) with modifications. Briefly, cultures grown as described above were standardized to 0.5 MacFarland, spread on the entire surface of $10 \mathrm{CBA}$ agar plates using sterile swabs and incubated anaerobically at $22^{\circ} \mathrm{C}$ for 15 days. After incubation, the agar (together with the grown culture) was cut into small cubes and pooled into a $1,000 \mathrm{ml}$

\footnotetext{
${ }^{14}$ https://www.eucast.org/ast_of_bacteria/guidance_documents/
}

beaker into which $150 \mathrm{ml}$ acetonitrile was added. The agar and the culture were left to soak for an hour then centrifuged at $12,000 \times g$ for $30 \mathrm{~min}$. The supernatant was collected, and the residue resuspended in $75 \mathrm{ml}$ acetonitrile then treated as before. The resulting supernatants were pooled together, and the volume increased to $400 \mathrm{ml}$ with acetonitrile. This resulted in formation of precipitates, which were separated by centrifuging two times $(8,000 \times g ; 5 \mathrm{~min})$. The crude extract was produced from the supernatant using a rotary evaporator at $30^{\circ} \mathrm{C}$ and stored in parafilm-sealed $5 \mathrm{ml}$ Eppendorf tube at $4^{\circ} \mathrm{C}$ for future use.

\section{Antimicrobial Activity of Putative Polyketide}

The antimicrobial activity of the crude polyketide extract was determined by disk diffusion method (Voitsekhovskaia et al., 2020) with modifications. Briefly, the crude extract was suspended in distilled water $(0.5 \mathrm{mg} / \mu \mathrm{l})$ and $50 \mu \mathrm{l}$ of the mixture loaded on sterile $6 \mathrm{~mm}$ disks (Whatman ${ }^{\circledR}$, United States). The loading was done in two subsequent steps of $25 \mu \mathrm{l}$ and drying under a hood for 2 h. L. monocytogenes EGDe and E. coli were grown as described above. E. devriesei K8-ED (Wambui et al., 2018) and Staphylococcus aureus RN4220 (Kreiswirth et al., 1983) were grown aerobically on BHI agar and Trypticase Soy agar, respectively, for $24 \mathrm{~h}$ at $37^{\circ} \mathrm{C}$. The two strains were standardized to $0.5 \mathrm{McF}$ arland and spread on respective media and the dried disks placed on top. The plates were incubated at $37^{\circ} \mathrm{C}$ and antimicrobial activity determined as presence of clear zones around the disks. Where inhibition zones were present, they were measured to the nearest $\mathrm{mm}$. All experiments were carried out in three biological replicates.

\section{Physical Characteristics of Putative Polyketide}

The physical activity of the crude polyketide extract was determined as previously described (Kuiper et al., 2004) with modifications. For the effect on the crude extract on surface tension of water, the crude extract was suspended in distilled water $(20 \mu \mathrm{g} / \mathrm{ml})$ and divided into two. Into one portion, crystal violet dye was added for visual contrast. To ensure that the dye had no effect on the surface tension, distilled water dyed with crystal violet was used as a control. Samples, $500 \mu$, were pipetted into $1 \mathrm{ml}$ cuvettes and the cuvettes left to stand in atmospheric air for $30 \mathrm{~min}$ at room temperature. Further effects of the extract on surface tension were carried out on non-polar surface using the drop collapse assay. $25 \mu$ l of dyed distilled water with $(20 \mu \mathrm{g} / \mathrm{ml})$ or without the crude extract was dropped on the surface of parafilm and left to stand at room temperature for $30 \mathrm{~min}$. The effect of the crude extract on water's meniscus in the cuvettes and collapse of the drop on parafilm was determined visually. For hygroscopic assay, $30 \mu \mathrm{g}$ of the crude extract was placed on a microscope slide cover glass and left to stand in atmospheric air for $12 \mathrm{~h}$ at room temperature. The hygroscopic potential was determined as the percentage change of the extract's weight after $12 \mathrm{~h}$. All experiments were carried out in three independent replicates.

\section{Data Analysis}

Data for biochemical characteristics of CGAS001 and physical characteristics of its putative polyketide extract were described 


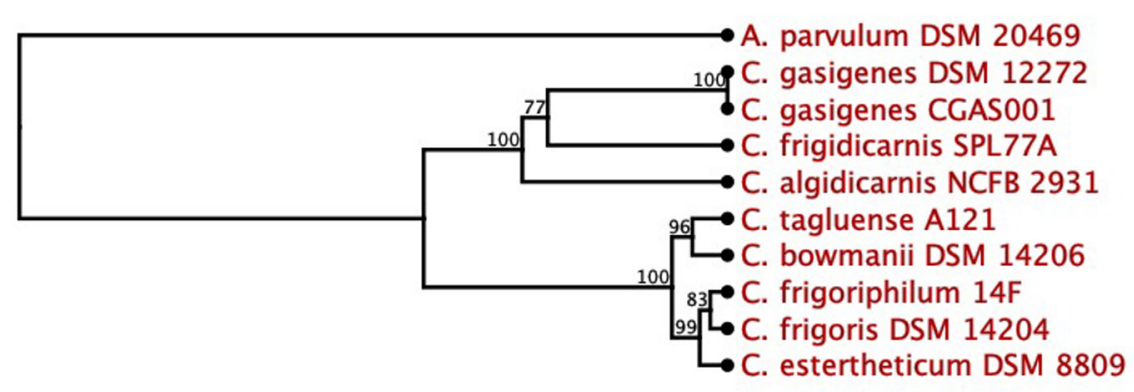

0.100

FIGURE 1 | Phylogenetic tree of Clostridium gasigenes CGAS001 by 16 S rRNA gene sequence. C. gasigenes CGAS001 and DSM 12272 formed a phylogenetic subunit distinct from selected blown pack spoilage causing Clostridium sensu stricto spp. strains. Atopobium parvulum DSM 20469 was used as the outgroup. Number at joint indicated bootstrap values (\%) while the bar indicates 0.1 substitutions per nucleotide position. Phylogenetic tree reconstructed by CLC Workbench Genomics based on alignment of the nucleotide sequences.

qualitatively. Zones of inhibitions for both antibiotic resistance profile of CGAS001 and the antimicrobial sensitivity of indicator strains to putative polyketide as well as the changes in weight of the putative polyketide after exposure to air were described as means and standard deviation. Where applicable, means were compared using the $t$-test $(p=0.05)$.

\section{RESULTS}

\section{Isolation of an Anaerobic Psychrophilic Clostridium spp. Strain}

Culturing of anaerobic psychrophilic Clostridium spp. was successful in one out of the 10 meat juice samples (MJS). The positive sample (ID = 1399/12) was MJS from vacuum packed lamb meat imported to Switzerland from New Zealand. Purified isolates from the sample formed gray, semi-translucent, raised, convex, shiny smooth circular colonies with entire margins that were $\beta$-hemolytic on Columbia blood agar supplemented with $5 \%$ sheep blood (CBA). Colonies were visible on CBA after 7 days of incubation in anaerobic conditions at $4^{\circ} \mathrm{C}$. Under the microscope $(100 \times)$, the isolates formed thick rods that stained blue. Subterminal spores were also visible in a few cells. On CBA, the isolates failed to grow at 25,30 , and $37^{\circ} \mathrm{C}$ in both aerobic and anaerobic conditions and at $4^{\circ} \mathrm{C}$ in aerobic conditions. A single typical colony from the ethanol treated sample was chosen for genome sequencing.

\section{Features of the Draft Genome}

The draft genome sequence of the isolate was assembled into 56 contigs and its size and Glycine-Cysteine (GC) content estimated to be $4.1 \mathrm{Mb}$ and 28.7\%, respectively. CheckM (Parks et al., 2015) predicted low levels of contamination in the genome $(0.81 \%)$. No foreign 16S rRNA fragments were detected by Contest16S (Lee et al., 2017). The annotated genome had 3,845 coding sequences. Ninety-five RNAs that included 9, 4 and 4 5S, 16S and 23S rRNAs, respectively, 75 tRNAs and 3 ncRNAs were predicted. The sequences of the four partial 16S rRNA genes were identical. No plasmids related genes were predicted.

\section{Genotypic Identification of Novel Clostridium gasigenes Strain CGAS001}

The 16S rRNA partial sequence of isolate, 1,319 bp $(88.9 \%$ complete), was $100 \%$ identical to that of C. gasigenes type strain DSM 12272 at a coverage of $83 \%$. A 16 S rRNA-based phylogenetic analysis of the two strains and seven BPS causing C. sensu stricto spp. revealed the isolate and C. gasigenes DSM 12272 clustered together (Figure 1). The two strains formed a larger mono-phylogenetic unit with $C$. algidicarnis NCFB 2931 and C. frigidicarnis SPL77A. At the whole genome sequence (WGS) level, the Average Nucleotide Identity (ANI) values between the isolate and six Clostridium spp. revealed the relationship, at $98.3 \%$ was closest between the isolate and C. gasigenes DSM 12272 while in the other tested Clostridium spp., the relationship ranged between 76.1 and $70.7 \%$ (Table 1). Moreover, the digital DNA-DNA hybridization $(\mathrm{dDDH})$ value between the isolate and the DSM 12272 was 98.3\%, which

TABLE 1 | The average nucleotide identity (ANI) and digital DNA-DNA hybridization $(\mathrm{dDDH})$ values calculated from the genomes of Clostridium gasigenes CGAS001 against five other strains from "Blown pack" spoilage causing Clostridium spp.

\begin{tabular}{lccc}
\hline Strains $^{\dagger}$ & ANI value (\%)* $^{*}$ & \multicolumn{2}{c}{$\mathbf{d D D H}$ value (\%) } \\
\cline { 3 - 4 } & & $\begin{array}{c}\text { For same } \\
\text { species }\end{array}$ & $\begin{array}{c}\text { For same } \\
\text { subspecies }\end{array}$ \\
\hline C. gasigenes DSM 12272 & 98.3 & 98.3 & 73.3 \\
C. frigidicarnis DSM 12271 & 71.8 & 0 & 0 \\
C. tagluense A121 & 71.4 & 0 & 0 \\
C. estertheticum DSM 14864 & 71.2 & 0 & 0 \\
C. estertheticum DSM 8809 & 70.8 & 0 & 0 \\
C. algidicarnis B3 & 70.7 & 0 & 0
\end{tabular}

${ }^{\dagger} \mathrm{C}$. gasigenes CGASO01 served as the reference strain. ${ }^{*}$ Calculated using OrthoANIu algorithm in EzBioCloud web server. The ANI cut-off value for the same species is $\geq 95 \%$ (Yoon et al., 2017b). ' Calculated using logistic regression (Formula 2) using Genome-to-Genome Distance Calculator web server. The subspecies dDDH cut-off value for the same species and subspecies are $\geq 70 \%$ and $\geq 79-80 \%$, respectively (Meier-Kolthoff et al., 2013). 


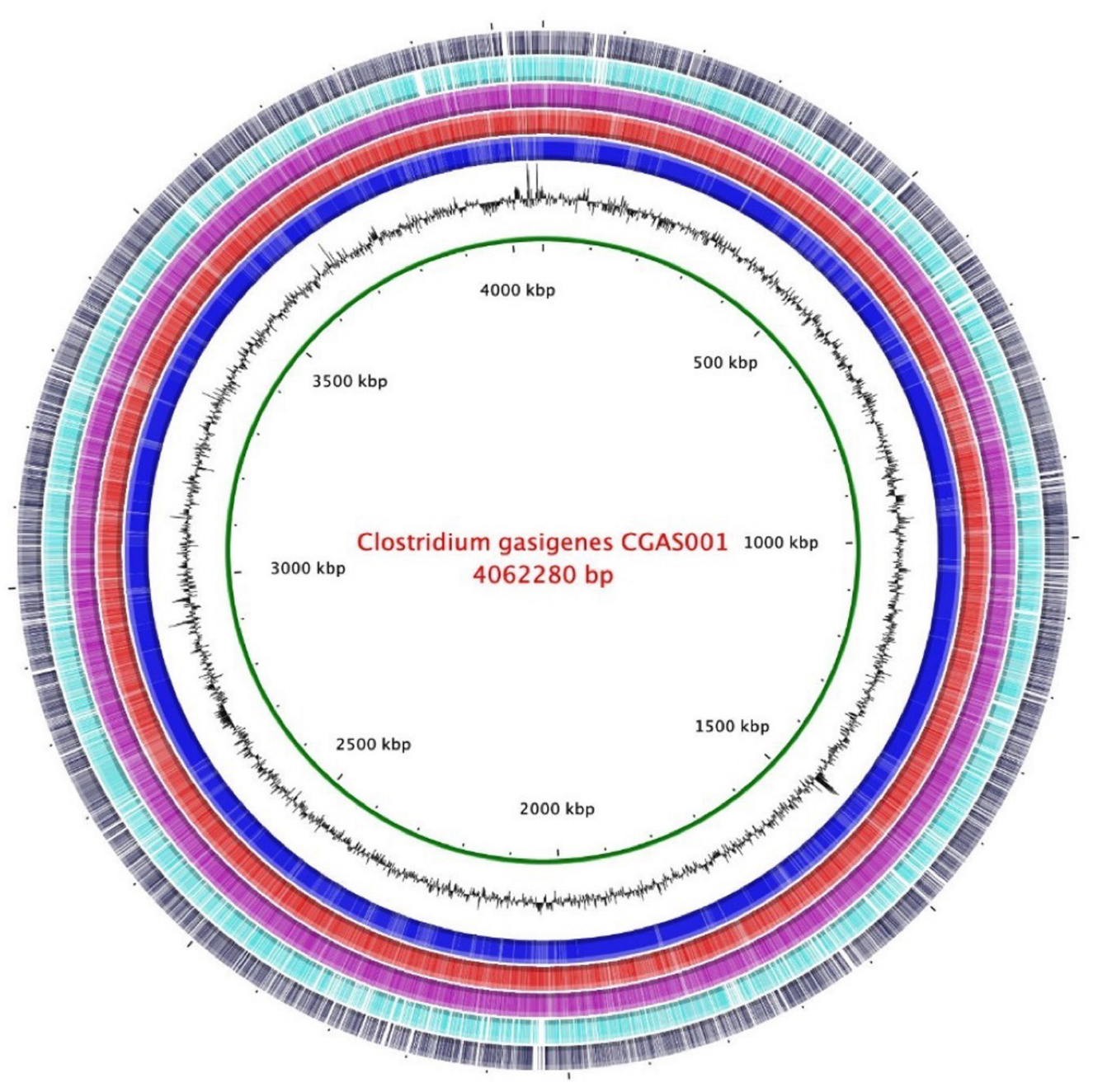

GC content

C. gasigenes

$100 \%$ identity

$70 \%$ identity

$50 \%$ identity

C. frigidicarnis

$100 \%$ identity

70\% identity

$50 \%$ identity

C. tagluense

$100 \%$ identity

$70 \%$ identity

$50 \%$ identity

C. algidicarnis

$100 \%$ identity

$70 \%$ identity

$50 \%$ identity

C. estertheticum

$100 \%$ identity

$70 \%$ identity

$50 \%$ identity

FIGURE 2 | Circular genomic map of C. gasigenes CGAS001 and selected genomes of five Clostridium species causing blown pack spoilage. There was a closer identity of CGAS001 strain CGAS001 to the only other sequenced C. gasigenes strain DSM 12272 than the other selected Clostridium species. The circular map produced using BRIG software.

was above the $70 \%$ threshold for a single species. On the other hand, the probability that the isolate and C. gasigenes DSM 12272 were related to the same subspecies was $73.3 \%$, which is below the $79 \%$ threshold for single subspecies. The relation of the genomes of the isolate to C. gasigenes DSM 12272 and selected WGS of psychrophilic Clostridium spp. causing BPS is presented in Figure 2. Based on these genotypic considerations, the isolate from sample 1399/12 was identified as a member of $C$. gasigenes species and assigned the strain name CGAS001. The isolate is henceforth referred by the name C. gasigenes CGAS001.

\section{General Metabolic Features Saccharolytic Features}

Both C. gasigenes CGAS001 and DSM 12272 encoded one $\alpha$-amalyse (CGAS001 peg.659), one pullulanase (CGAS001 peg.977) and three neopullulanases (CGAS001 peg.980, 1572, 3743, and 3749) (Supplementary Table S1). C. gasigenes
CGAS001 and DSM 12272 had 17 and 19 genes, respectively, encoding phosphotransferase system (PTS) component IIC of the PTS systems. All of these could be categorized into six of the seven major PTS subclasses namely; glucose, fructose, lactose, galactitol, mannose, and L-ascorbate families. CGAS001 encoded one xylanase (CGAS001 peg.512) (Supplementary Table S1) unlike DSM 12272, which did not (Supplementary Table S2), but paled in comparison to C. estertheticum representative strains that had 7 to 9 putative xylanases. Saccharolytic activity of CGAS001 was demonstrated by a positive starch hydrolysis test. Furthermore, the API20A kit demonstrated the strain's ability to utilize and produce acids in different carbohydrates among them D-mannitol, D-maltose, D-salicin, D-xylanose, Dcellobiose, D-mannose, D-melezitose, and D-trehalose. Both CGAS001 and DSM 12272 encoded five chitinases among which, four (CGAS001 peg.620-623) formed a cluster that is present in C. gasigenes species (Supplementary Table S1), and absent in genomes of the other clostridia strains. 


\section{Lipolytic, Lecithinase and Proteolytic Features}

CGAS001 encoded four phospholipases (CGAS001 peg.290, 308, 1564, and 1959) (Supplementary Table S1) compared to three phospholipases in the DSM 12272 (Supplementary Table S2). In the other Clostridium spp., only C. frigidicarnis DSM $12271(n=5)$ encoded more phospholipases. There were five lipases/esterases in strain CGAS001 (Supplementary Table S1) compared to four in strain DSM 12272 (Supplementary Table S2). Consistent with the genome, CGAS001 showed both lipolytic and lecithinase activities. Genes coding for proteolytic enzymes were present in the genome of strain CGAS001, including a microbial collagenase (CGAS001 peg.634) and Alphaclostripain precursor (CGAS001 peg.1562) (Supplementary Table S1). Preliminary phenotypic characterization showed CGAS001 had proteolytic activity on skim milk. A putative cysteine protease (CGAS001 peg.3272: herein referred to CysP for Cysteine Protease) (Supplementary Table S1), which was predicted to have a signal peptide, was identified. cys $P$ gene was present and localized adjacent to $\mathrm{rec} X$ gene in $C$. gasigenes 12272 (Supplementary Table S2) and the other Clostridium spp. genomes. CysP protein sequences in all five Clostridium species shared a conserved GEW motif in the C-terminal.

\section{Virulence Factors}

Twenty-two potential virulence factors grouped into 16 classes were predicted in C. gasigenes CGAS001 (Table 2). A putative clostridiolysin biosynthetic gene cluster (CGAS001 peg.19621970) was identified in CGAS001 (Supplementary Table S1). The same gene cluster was present in DSM 12272 (Supplementary Table S2). The presumptive clostridiolysin-like protein precursor (CGAS001 peg.1962) was 51 aa long in both strains, but CGAS001 had an extra 50 aa encoded protein (CGAS001 peg.1961) adjacent to the precursor (Supplementary Table S1). Among the other Clostridium spp. strains, the clostridiolysinlike biosynthetic cluster was only identified in C. algidicarnis B3 and C. frigidicarnis DSM 12271 with the latter encoding two more proteins (52 and 53 aa) adjacent to its precursor (52 aa) (Figure 3). A CDS for an exfoliative toxin A (CGAS001 peg.1361) was also identified in the genomes of both C. gasigenes strains (Supplementary Tables S1, S2) as well as, C. frigidicarnis DSM 12271 and C. tagluense A121. Despite of these virulence factors, strain CGAS001 was determined to be a non-human pathogen (probability $=0.2$ ). Similar predictions were made for C. gasigenes DSM 12272 strain whose probability was 0.3 .

\section{Antibiotic and Stress Resistance Genes}

Annotation in RAST web server identified 53 genes coding for stress resistance in C. gasigenes CGAS001. Some of the roles of protein encoded by these genes are listed in Table 3 . These included resistance to tetracycline, chloramphenicol, beta lactamases and fluoroquinolone. There were also proteins involved in arsenic, cadmium, cobalt-zinc-cadmium and copper resistance. No known chloramphenicol resistance proteins were annotated in DSM 12272 (Supplementary Table S2). A protein annotated as "Daunorubicin resistance transmembrane protein" (CGAS001 peg.632) was also identified (Supplementary Table S1). Domain search revealed the protein was an ABC-2
TABLE 2 | Potential virulence factors in the genome of Clostridium gasigenes CGAS001*.

\begin{tabular}{|c|c|c|}
\hline VF class & Virulence factors & Related genes \\
\hline \multirow[t]{3}{*}{ Adherence } & Fibronectin-binding protein & Fbp \\
\hline & GroEL & groEL \\
\hline & LPS O-antigen & $w b p l$ \\
\hline \multirow{4}{*}{ Regulation } & CheA/CheY (Isteria) & chey \\
\hline & isR/IisK (listeria) & lisR \\
\hline & LisR/LisK (Listeria) & lish \\
\hline & VirR/VirS (Listeria) & virR \\
\hline \multirow[t]{3}{*}{ Toxin } & Alpha-clostripain & closl \\
\hline & Hemolysin & Undetermined \\
\hline & & Undetermined \\
\hline Copper uptake & $\begin{array}{l}\text { Copper exporter } \\
\text { (Mycobacterium) }\end{array}$ & $\operatorname{ctpV}$ \\
\hline Glycosylation system & $\begin{array}{l}\text { O-linked flagellar } \\
\text { glycosylation } \\
\text { (Campylobacter) }\end{array}$ & neuB2 \\
\hline \multirow[t]{5}{*}{ Immune evasion } & Capsule (Staphylococcus) & capF \\
\hline & & capG \\
\hline & & 41 \\
\hline & $\begin{array}{l}\text { Polysaccharide capsule } \\
\text { (Bacillus) }\end{array}$ & galE \\
\hline & & gtaB \\
\hline Intracellular survival & $\begin{array}{l}\text { Sugar-uptake system } \\
\text { (Listeria) }\end{array}$ & $h p t$ \\
\hline Iron uptake & $\begin{array}{l}\text { Periplasmic binding } \\
\text { protein-dependent ABC } \\
\text { transport systems (Vibrio) }\end{array}$ & $\operatorname{vctC}$ \\
\hline $\begin{array}{l}\text { Lipid and fatty acid } \\
\text { metabolism }\end{array}$ & $\begin{array}{l}\text { Pantothenate synthesis } \\
\text { (Mycobacterium) }\end{array}$ & panD \\
\hline Magnesium uptake & $\begin{array}{l}\mathrm{Mg}^{2+} \text { transport } \\
\text { (Salmonella) }\end{array}$ & mgtB \\
\hline Motility & Flagella (Helicobacter) & fliP \\
\hline Others & O-antigen (Yersinia) & $d d h \mathrm{~A}$ \\
\hline Phagosome arresting & $\begin{array}{l}\text { Nucleoside diphosphate } \\
\text { kinase (Mycobacterium) }\end{array}$ & $n d k$ \\
\hline Secretion system & $\begin{array}{l}\text { Type III secretion system } \\
\text { (Chlamydia) }\end{array}$ & $c d s \mathrm{~N}$ \\
\hline $\begin{array}{l}\text { Serum resistance and } \\
\text { immune evasion }\end{array}$ & LPS (Francisella) & $w b t \mathrm{E}$ \\
\hline Stress adaptation & $\begin{array}{l}\text { Catalase-peroxidase } \\
\text { (Mycobacterium) }\end{array}$ & katG \\
\hline
\end{tabular}

*Identified in Virulence Finder Database (VFDB) 2019 web server.

type transporter $\left(E\right.$-value $\left.=2.19 \mathrm{e}^{-37}\right)$, hence forming an $\mathrm{ABC}$ transporter gene cluster with two other proteins annotated as "Efflux ABC transporter, permease protein" (CGAS001 peg.631) and "Efflux ABC transporter, ATP-binding protein" (CGAS001 peg.633) in a what seems to be a gene cluster of $3 \mathrm{ABC}$ transporters. Further analysis revealed this cluster was only present in C. gasigenes DSM 12272 (Supplementary Table S2) and C. algidicarnis B3. Although antibiotic resistance genes were encoded in the genome of CGAS001, the strain showed high sensitivity to all antibiotics tested (zones of inhibition $>30 \mathrm{~mm}$ ) apart from polymyxin B and streptomycin, which had no effect on the strain's growth. 
TABLE 3 | Stress resistance subsystems in the genome of Clostridium gasigenes CGASO01*.

\begin{tabular}{|c|c|}
\hline Subsystem & Role \\
\hline \multirow[t]{2}{*}{ Arsenic resistance } & Arsenical pump-driving ATPase (EC 3.6.3.16) \\
\hline & Arsenical resistance operon trans-acting repressor ArsD \\
\hline \multirow[t]{2}{*}{ Beta-lactamase } & Beta-lactamase repressor Blal \\
\hline & Beta-lactamase (EC 3.5.2.6) \\
\hline \multirow{2}{*}{$\begin{array}{l}\text { Cadmium } \\
\text { resistance }\end{array}$} & Cadmium-transporting ATPase (EC 3.6.3.3) \\
\hline & Cadmium efflux system accessory protein \\
\hline \multirow{3}{*}{$\begin{array}{l}\text { Cobalt-zinc- } \\
\text { cadmium } \\
\text { resistance }\end{array}$} & DNA-binding heavy metal response regulator \\
\hline & Cobalt-zinc-cadmium resistance protein \\
\hline & Transcriptional regulator, MerR family \\
\hline \multirow{4}{*}{$\begin{array}{l}\text { Copper } \\
\text { homeostasis: } \\
\text { copper tolerance }\end{array}$} & Copper chaperone \\
\hline & Copper-translocating P-type ATPase (EC 3.6.3.4) \\
\hline & Multicopper oxidase \\
\hline & Cytoplasmic copper homeostasis protein CutC \\
\hline \multirow{4}{*}{$\begin{array}{l}\text { Multidrug } \\
\text { Resistance Efflux } \\
\text { Pumps }\end{array}$} & Macrolide export ATP-binding/permease protein MacB (EC \\
\hline & 3.6.3.-) \\
\hline & $\begin{array}{l}\text { Multidrug-efflux transporter, major facilitator superfamily } \\
\text { (MFS) (TC 2.A.1) }\end{array}$ \\
\hline & $\begin{array}{l}\text { Multi antimicrobial extrusion protein [ } \mathrm{Na}(+) / \text { drug antiporter] } \\
\text { MATE family of MDR efflux pumps }\end{array}$ \\
\hline \multirow{3}{*}{$\begin{array}{l}\text { Resistance to } \\
\text { fluoroquinolones }\end{array}$} & Efflux pump Lde \\
\hline & DNA gyrase subunit A (EC 5.99.1.3) \\
\hline & DNA gyrase subunit B (EC 5.99.1.3) \\
\hline $\begin{array}{l}\text { Resistance to } \\
\text { Vancomycin }\end{array}$ & Vancomycin B-type resistance protein VanW \\
\hline $\begin{array}{l}\text { Streptothricin } \\
\text { resistance }\end{array}$ & $\begin{array}{l}\text { Streptothricin acetyltransferase, Streptomyces lavendulae } \\
\text { type }\end{array}$ \\
\hline \multirow{2}{*}{$\begin{array}{l}\text { Tetracycline } \\
\text { resistance, } \\
\text { ribosome } \\
\text { protection type }\end{array}$} & $\begin{array}{l}\text { Ribosome protection-type tetracycline resistance related } \\
\text { proteins, group } 2\end{array}$ \\
\hline & Translation elongation factor $\mathrm{G}$ \\
\hline Zinc resistance & $\begin{array}{l}\text { Response regulator of zinc sigma-54-dependent } \\
\text { two-component system }\end{array}$ \\
\hline
\end{tabular}

*Annotated in RAST web server.

\section{Spore Related Coding Sequences}

Proteins related to spore stress resistance, namely six small acid soluble spore proteins (SASPs), were identified (Supplementary Table S1). Three of the SASPs (61 aa each) were in a gene cluster (CGAS001 peg.1080-1082). Fourth, fifth and sixth SASPs were 61, 60, and 84 aa long (CGAS001 peg.1166, 17363249 , respectively). The sequences of the six CGAS001 SASPs were $100 \%$ identical to those of C. gasigenes 12272 (Supplementary Table S1). Only C. estertheticum strains encoded equal or more ( $n=6$ or 7) SASPs than the two C. gasigenes strains. Furthermore, gene clusters for at least three SASPs were identified in C. estertheticum representative genomes whereby four SAPS clustered together. Both strains
TABLE 4 | Proteins, among them polyketide synthesis proteins, encoded by a gene cluster within the genome of Clostridium gasigenes CGAS001*.

\begin{tabular}{|c|c|c|c|}
\hline Contig & Gene & Length (aa) & Predicted protein \\
\hline 22 & 3765 & 220 & $\begin{array}{l}\text { Macrolide export } \\
\text { ATP-binding/permease protein MacB }\end{array}$ \\
\hline 23 & 3766 & 1554 & $\begin{array}{l}\text { Polyketide synthase modules and } \\
\text { related proteins }\end{array}$ \\
\hline 23 & 3767 & 637 & $\begin{array}{l}\text { ABC transporter, } \\
\text { permease/ATP-binding protein }\end{array}$ \\
\hline 23 & 3768 & 252 & $\begin{array}{l}\text { ABC transporter-like sensor } \\
\text { ATP-binding protein }\end{array}$ \\
\hline 23 & 3769 & 229 & Putative thioesterase \\
\hline 23 & 3770 & 560 & $\begin{array}{l}\text { Efflux ABC transporter, } \\
\text { permease/ATP-binding protein }\end{array}$ \\
\hline 24 & 3774 & 323 & sensor histidine kinase \\
\hline 24 & 3775 & 175 & $\begin{array}{l}\mathrm{ABC} \text { transporter-like sensor linked } \\
\text { response regulator }\end{array}$ \\
\hline 24 & 3776 & 39 & hypothetical protein \\
\hline 24 & 3777 & 238 & ABC transporter, ATP-binding protein \\
\hline 24 & 3778 & 829 & $\begin{array}{l}\text { ABC transporter, } \\
\text { permease/ATP-binding protein }\end{array}$ \\
\hline 24 & 3779 & 339 & $\begin{array}{l}\text { Polyketide synthase modules and } \\
\text { related proteins }\end{array}$ \\
\hline 25 & 3780 & 3025 & $\begin{array}{l}\text { Polyketide synthase modules and } \\
\text { related proteins }\end{array}$ \\
\hline 33 & 3814 & 1130 & $\begin{array}{l}\text { Polyketide synthase modules and } \\
\text { related proteins }\end{array}$ \\
\hline 35 & 3818 & 898 & $\begin{array}{l}\text { Polyketide synthase modules and } \\
\text { related proteins }\end{array}$ \\
\hline 36 & 3819 & 710 & $\begin{array}{l}\text { Polyketide synthase modules and } \\
\text { related proteins }\end{array}$ \\
\hline 36 & 3820 & 171 & Long-chain-fatty-acid-CoA ligase \\
\hline 37 & 3821 & 156 & Long-chain-fatty-acid-CoA ligase \\
\hline 37 & 3822 & 610 & $\begin{array}{l}\text { Polyketide synthase modules and } \\
\text { related proteins }\end{array}$ \\
\hline 38 & 3823 & 339 & Mobile element protein \\
\hline 38 & 3824 & 168 & hypothetical protein \\
\hline 39 & 3825 & 574 & $\begin{array}{l}\text { Polyketide synthase modules and } \\
\text { related proteins }\end{array}$ \\
\hline 40 & 3826 & 442 & Mobile element protein \\
\hline 41 & 3827 & 517 & $\begin{array}{l}\text { Polyketide synthase modules and } \\
\text { related proteins }\end{array}$ \\
\hline 42 & 3828 & 311 & Mobile element protein \\
\hline 43 & 3829 & 251 & hypothetical protein \\
\hline 43 & 3830 & 169 & Long-chain-fatty-acid-CoA ligase \\
\hline
\end{tabular}

*Annotated in RAST web server.

CGAS001 and C. gasigenes 12272 possessed similar sporulating proteins, most of which were 100\% conserved (Supplementary Table S1). The only distinction between the two strains was a presumptive cotJ operon (CGAS001 peg.3684-3686) coding for proteins annotated as "Protein CotJA," "Polypeptide composition of the spore coat protein CotJB," and "Manganese catalase (EC 1.11.1.6) $\geq$ Spore coat protein CotJC." The presumptive operon was only present in C. gasigenes CGAS001. The other Clostridium spp. strains had the cotJABC genes clusters apart from C. frigidicarnis DSM 12271. In C. estertheticum, two separate clusters of $\cot J$ operons were found. 


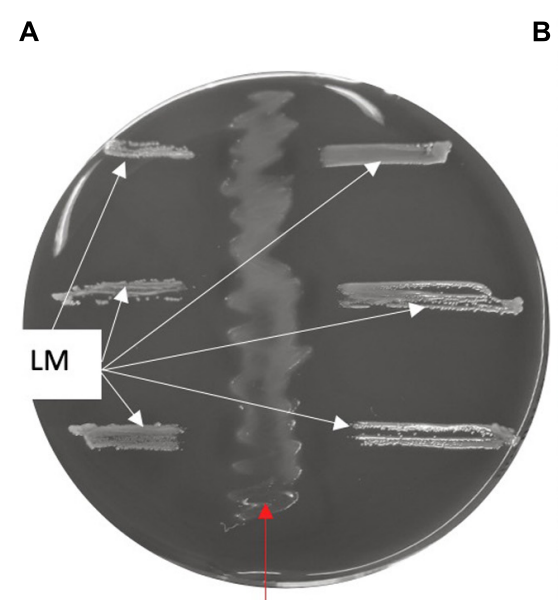

CG

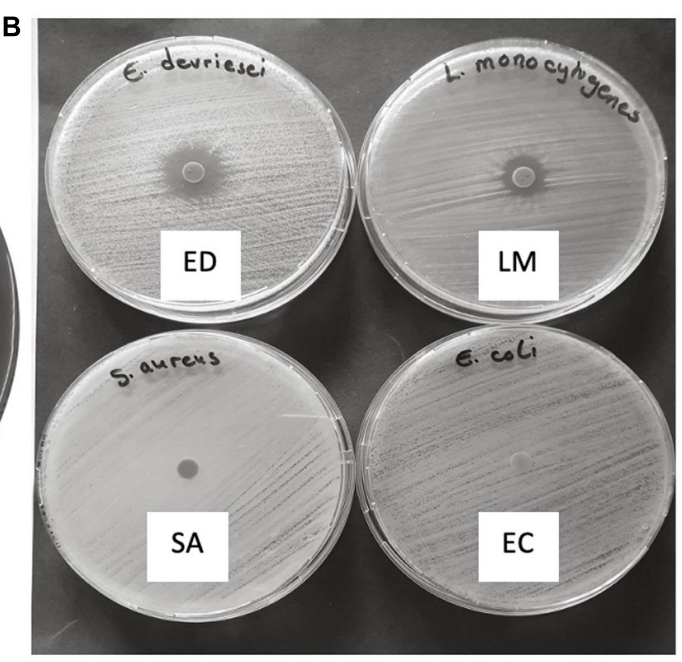

FIGURE 3 | Antimicrobial activity of C. gasigenes CGAS001 crude polyketide extract. (A) The potential of CGAS001 to synthesize antimicrobial compounds was initially identified using the agar streak method whereby the growth of Listeria monocytogenes EGDe (LM) was inhibited by CGAS001 (CG). (B) The crude extract showed narrow spectrum antimicrobial activity against selected Gram-positive and negative bacteria using the disk diffusion method. The extract was active against L. monocytogenes EGDe and Enterococcus devriesei K8-ED (ED), but inactive against Staphylococcus aureus (SA) and Escherichia coli (EC).

\section{Cryptic Polyketide Synthesis Genes}

Clostridium gasigenes CGAS001 harbored genes involved in the biosynthesize of polyketides (Supplementary File S1). The genes were localized in a cluster of more than 60 encoded proteins some of which, including nine proteins polyketide synthase modules and related proteins, a twocomponent system and seven $\mathrm{ABC}$ type transporters, are listed in Table 4. Similar clusters with proteins annotated as polyketide synthase modules and related proteins, were only identified in C. frigidicarnis DSM 12271, which encoded twenty proteins. The presence of a bioactive putative polyketide was initially identified phenotypically by inhibitory activity against L. monocytogenes EGDe through the cross-streak assay (zone of inhibition $=10.6 \pm 0.5 \mathrm{~mm}$ ) (Figure 3A). Furthermore, the crude extract showed antimicrobial activity against $L$. monocytogenes EGDe and E. devriesei K8-ED (zones of inhibition $=12.6 \pm 0.5$ and $16.0 \pm 0.0 \mathrm{~mm}$, respectively) (Figure 3B), with E. devriesei being more inhibited than L. monocytogenes EGDe $(p<0.05)$. The crude extract showed no activity against $S$. aureus RN4220 and E. coli (Figure 3B). Besides the antimicrobial activity, the putative polyketide demonstrated biosurfactant activity as determined by its effect on water surface tension evident in the collapse of water droplets (Figures $4 \mathbf{A}, \mathbf{B}$ ) and effect on the meniscus of distilled water with the compound (Figure 4C). Furthermore, the extract was hygroscopic following $3.5 \pm 0.5 \%$ increase in weight after $12 \mathrm{~h}$ exposure to air $(p<0.05)$.

\section{DISCUSSION}

Clostridium gasigenes is among the important and recognized causative agents for BPS of refrigerated vacuum-packed meat (Broda et al., 2000; Moschonas et al., 2011a; Silva et al., 2011). Genomic studies for the species are nonetheless lacking. In this regard, the present study characterized the genome of a novel C. gasigenes strain CGAS001 isolated from meat juice sample of vacuum-packed lamb meat imported to Switzerland from New Zealand by comparing it with the type strain C. gasigenes 12272 and five other clostridia strains from four BPS-causing Clostridium sensu stricto species namely; C. algidicarnis B3, C. estertheticum subsp. estertheticum DSM 8809, C. estertheticum subsp. laramiense DSM 14864, C. frigidicarnis DSM 12271 and C. tagluense A121. The successful isolation of the C. gasigenes CGAS001 occurred in one of the 10 real time-PCR positive samples identified in a recent study (Wambui et al., 2020).

In silico methods namely, average nucleotide identity (ANI) and digital DNA-DNA Hybridization ( $\mathrm{dDDH}$ ) have been widely applied to identify bacteria whereby for a bacteria species, the cutoff values for ANI and $\mathrm{dDDH}$ are $\geq 95 \%$ and $\geq 70 \%$, respectively (Meier-Kolthoff et al., 2013, 2014; Chun et al., 2018). The ANI values between C. gasigenes CGAS001 and C. gasigenes DSM 12272 were above the threshold for a species, thus the two could be affiliated to the same species. On the other hand, the subspecies $\mathrm{dDDH}$ cut-off value for a similar bacteria subspecies is $\geq 79-80 \%$ (Meier-Kolthoff et al., 2014). The value for the strains CGAS001 and DSM 12272 was below the subspecies dDDH threshold (Table 1), indicating two subspecies delineation for both strains. Hence CGAS001 can be regarded as a novel subspecies of C. gasigenes.

Clostridium gasigenes occurs in numerous environments (Moschonas et al., 2009; Silva et al., 2011) requiring a multitude of metabolic enzymes for successful habitat colonization. Direct or indirect contact of meat with these environments may influence contamination of meat with the bacteria. In this regard, a combined action of several saccharolytic enzymes is necessary for complete degradation of starch (Sebaihia et al., 2007), hence the identification of $\alpha$-amalyse, pullulanase and neopullulanases suggest that strain CGAS001 is cable of complete 
$\mathbf{A}$

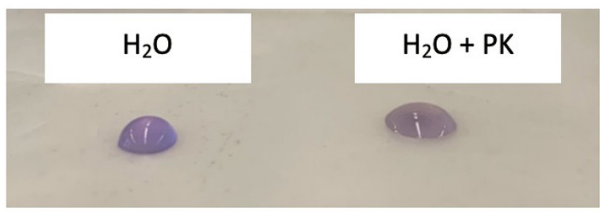

B

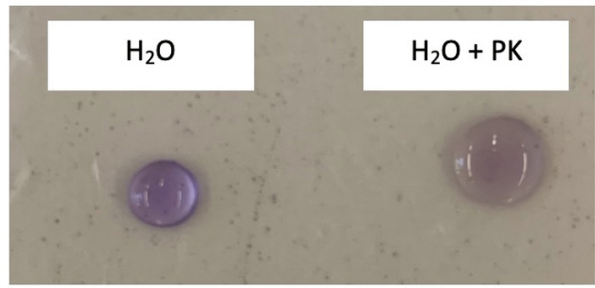

C

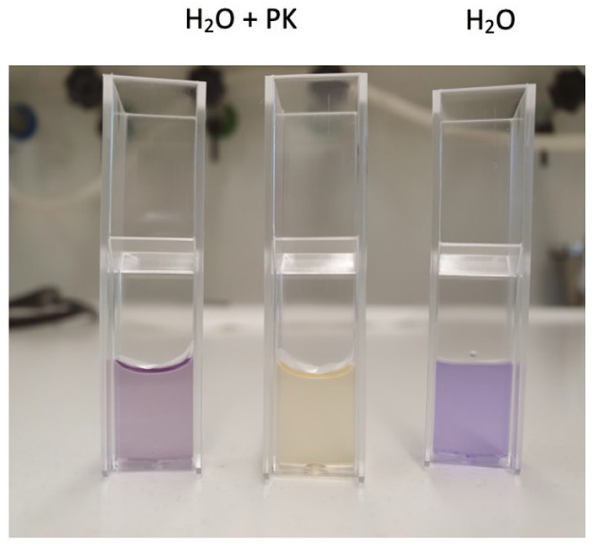

FIGURE 4 | Biosurfactant activity of C. gasigenes CGAS001's crude polyketide extract. Addition of the crude extract to distilled water (20 $\mu$ g/ml) affected the surface tension of the water. Distilled water without the extract was used as a control. Samples were left to stand in atmospheric air for 30 min at room temperature. Crystal violet was added to the mixture for visual effect and had no influence on the surface tension of the distilled water. (A) Front view and (B) top view of $25 \mu l$ droplets of distilled water with $\left(\mathrm{H}_{2} \mathrm{O}+\mathrm{PK}\right)$ or without $\left(\mathrm{H}_{2} \mathrm{O}\right)$ the extract on a non-polar surface (parafilm) after 30 min. (C) Five hundred microliter of distilled water with $\left(\mathrm{H}_{2} \mathrm{O}+\mathrm{PK}\right)$ or without $\left(\mathrm{H}_{2} \mathrm{O}+\mathrm{PK}\right)$ the polyketide extract in $1 \mathrm{ml}$ cuvettes after $30 \mathrm{~min}$.

starch hydrolysis and can inhabit starch rich environment. This was validated by the starch hydrolysis assay showing that CGAS001 could hydrolyze starch similar to DSM 12272 (Broda et al., 2000). In same previous study, strain DSM 12272 did not utilize xylose (Broda et al., 2000), which was confirmed by the absence of xylanase in its genome (Supplementary Table S2). Conversely, xylose was utilized by CGAS001 using the API20A test kit, which can be attributed to the presence of a xylanase in its genome. Xylanases hydrolyze xylan, a hemicellulose that is highly abundant in nature (Walia et al., 2017). The ability of CGAS001 to utilize other saccharides may result from the PTS systems encoded by its genome. A key feature of the CGAS001, which was also reported for other C. gasigenes strains (Silva et al., 2011), was its inability to utilize glucose.

Lipolytic and proteolytic enzymes have a strong effect on the quality of meat and other proteinaceous and fatty foods in general. Enzymes secreted by psychrotrophic and psychrophilic bacteria can cause spoilage at refrigeration temperatures (von Neubeck et al., 2015; Zhu et al., 2017), thus the identification of lipases encoded by CGAS001 and the confirmation of their activities support the existence of complex enzymatic systems in CGAS001 necessary for proliferation in meat and potential to cause meat spoilage. On the other hand, a putative cysteine protease, CysP, with a signal peptide in the $\mathrm{N}$-terminus suggests the ability of CGAS001 to express proteases into the extracellular milieu, which was demonstrated by proteolytic activity on casein in the Nutrient agar supplemented with skim milk. Furthermore, a conserved WEG motif in CysP's C-terminus in four Clostridium spp. is suggestive of a functional importance of the motif, but so far, the protein has not been characterized.

Several toxins, among them hemolysins/phospholipases and clostidiolysin-like encoding genes affirm both the hemolytic and lecithinase phenotypes of CGAS001 identified in the type strain DSM 12272 (Broda et al., 2000). The presence of the hemolysins and lecithinases was consistent with hemolysis on
CBA and lecithinase activity on PYGS agar supplemented with egg yolk emulsion. On the other hand, a CDS annotated as Phospholipase/lecithinase/hemolysin that was unique only to the genomes of CGAS001 (Supplementary Table S1) and it had a homologous coding gene $C$. tagluense A121. It is unknown whether encoded proteins confer unique phenotypes in these strains. Despite of this, pathogenic potential predictions made presently for both C. gasigenes strains and the earlier in vivo assay for DSM 12272 (Broda et al., 2000) suggest that C. gasigenes species is non-pathogenic to humans.

CGAS001 possess several antimicrobial resistance genes (ARGs) (Table 3), similar to the report for C. estertheticum DSM 8809 (Yu et al., 2016). The presence of resistance genes does not always correspond to phenotypic responses (Eitel et al., 2013). This was confirmed by the antimicrobial resistance assay whereby CGAS001 was phenotypically only resistant against streptomycin and polymyxin B. As previously reported, polymyxin B has no activity against Gram-positive and anaerobic bacteria (Zavascki et al., 2007). However, this is the first report of streptomycin resistance in a BPS-causing clostridia species. The resistance mechanisms and the risk of transfer of the resistance to other bacteria warrant further investigation. Non-pathogenic organisms have been reported to transfer ARGs to pathogenic bacteria of clinical significance (Rossolini et al., 2008).

Small acid soluble proteins (SASPs) confer moist heat, UV radiation, hydrogen peroxide, hydrochloric acid, nitrous acid and formaldehyde resistance to clostridial spores (Raju et al., 2007; Paredes-Sabja et al., 2008). Their identification in the genome of CGAS001 and other BPS causing Clostridium spp. makes the SASPs potential biomarkers that can be targeted as a means of controlling BPS. Spore coats, including CotJABC proteins, are also important for spore germination and/resistance (Henriques et al., 1995). Previously, only Bacillus cereus and Bacillus subtilis were reported to encode all CotJABC proteins (Henriques and Moran, 2007; Aronson, 2018), despite a previous study showing 
an ORF adjacent to $\cot J B$ was co-transcribed with $\cot J B$ and cotJC in Clostridium novyi-NT (Bettegowda et al., 2006). The present study led to the identification of putative CotJA encoded in the genome of CGAS001 (Supplementary Table S1) and other Clostridium spp. strains indicating that the strains possess all CotJABC proteins thus affirming the study in C. novyi-NT. The fact that C. gasigenes DSM 12272 (Supplementary Table S2) and C. frigidicarnis DSM 12271 lack the cotJ operon indicted its presence is variable among Clostridium spp.

The genome of CGAS001 revealed cryptic gene clusters for polyketide biosynthesis. Polyketides are natural products widely used for their antibiotic, anticancer, immunosuppressive, and cholesterol-lowering properties (Shimizu et al., 2017). Presently, we have shown that CGAS001 produces a putative polyketide, which is consistent with its genome analysis. Production of secondary metabolites is an adaptation by producer strains to effectively compete in respective niches. The demonstration that CGAS001 encodes and produces polyketide with antimicrobial activity, although at a narrow spectrum, shows one of the adaptive features that may enhance its ability to grow and cause spoilage in meat. Further characterization indicated the polyketide has both hygroscopic and biosurfactant properties. The identification of orphan putative polyketide synthase modules in C. frigidicarnis DSM 12271 further makes the BPScausing clostridia a promising niche for the discovery of novel metabolites, including antimicrobial compounds. In Clostridium spp., only a limited number of antimicrobial products have been identified, isolated and characterized (Pahalagedara et al., 2020). Further research involving purification and detailed characterization of the polyketide will be carried out in future by our laboratory.

\section{CONCLUSION}

Whole genome sequence analysis determined that $C$. gasigenes CGAS001 and DSM 12272 constitute a single species, but are genetically distinct at subspecies level, making this the first report for a possible subspeciation in C. gasigenes. Metabolically, CGAS001 is saccharolytic, lipolytic and proteolytic. A xylanase encoding gene and ability to utilize xylose distinguish CGAS001 from the type strain DSM 12272.

\section{REFERENCES}

Adam, K. H., Flint, S. H., and Brightwell, G. (2010). Psychrophilic and psychrotrophic clostridia: sporulation and germination processes and their role in the spoilage of chilled, vacuum-packaged beef, lamb and venison. Int. J. Food Sci. Technol. 45, 1539-1544. doi: 10.1111/j.1365-2621.2010. 02320.x

Adam, K. H., Flint, S. H., and Brightwell, G. (2013). Reduction of spoilage of chilled vacuum-packed lamb by psychrotolerant clostridia. Meat Sci. 93, 310-315. doi: 10.1016/j.meatsci.2012.09.011

Alikhan, N. F., Petty, N. K., Ben Zakour, N. L., and Beatson, S. A. (2011). Blast ring image generator (BRIG): simple prokaryote genome comparisons. BMC Genomics 12:402. doi: 10.1186/1471-2164-12-402

Almalki, M. A. (2020). Isolation and characterization of polyketide drug molecule from Streptomyces species with antimicrobial activity against clinical pathogens. J. Infect. Public Health 13, 125-130. doi: 10.1016/j.jiph.2019.07.002
Genes for tetracycline, chloramphenicol, beta lactamases and fluoroquinolone resistance are present, but no phenotypic resistance was observed for the antibiotics. However, the strain is resistant to both polymyxin B and streptomycin. The genome is further characterized by toxin encoding genes among them phospholipases/haemolysins/lecithinases whose activity has been observed in vitro. CGAS001 has potential for novel antimicrobial synthesis owing to the nine identified orphan polyketide synthase modules and the confirmation of antimicrobial activity of a crude polyketide extract against L. monocytogenes and E. devriesei. Future molecular and phenotypic studies will be undertaken to characterize the functional roles for the genes identified.

\section{DATA AVAILABILITY STATEMENT}

The whole-genome shotgun project of the CGAS001 strain has been deposited in GenBank under the accession number JAAVWW010000000. The version described in this paper is the first version, accession number JAAVWW010000000.

\section{AUTHOR CONTRIBUTIONS}

RS, JW, and SC designed the study. RS supervised the study. JW and NC performed the experiments. JW performed genomic analyses. JW and RS wrote and revised the manuscript. All authors contributed to the article and approved the submitted version.

\section{ACKNOWLEDGMENTS}

We thank Marc J. A. Stevens for his help in the assembly and annotation of the sequence.

\section{SUPPLEMENTARY MATERIAL}

The Supplementary Material for this article can be found online at: https://www.frontiersin.org/articles/10.3389/fmicb. 2020.02048/full\#supplementary-material

Arasu, M. V., Duraipandiyan, V., Agastian, P., and Ignacimuthu, S. (2008). Antimicrobial activity of Streptomyces spp. ERI-26 recovered from Western Ghats of Tamil Nadu. J. Mycol. Med. 18, 147-153. doi: 10.1016/j.mycmed.2008. 07.004

Aronson, A. (2018). Regulation of expression of a select group of Bacillus anthracis spore coat proteins. FEMS Microbiol. Lett. 365:fny063. doi: 10.1093/femsle/ fny063

Bettegowda, C., Huang, X., Lin, J., Cheong, I., Kohli, M., Szabo, S. A., et al. (2006). The genome and transcriptomes of the anti-tumor agent Clostridium novyi-NT. Nat. Biotechnol. 24, 1573-1580. doi: 10.1038/nbt 1256

Bolton, D. J., Carroll, J., and Walsh, D. (2015). A four-year survey of blown pack spoilage Clostridium estertheticum and Clostridium gasigenes on beef primal cuts. Lett. Appl. Microbiol. 61, 153-157. doi: 10.1111/lam.12431

Brettin, T., Davis, J. J., Disz, T., Edwards, R. A., Gerdes, S., Olsen, G. J., et al. (2015). RASTtk: a modular and extensible implementation of the RAST algorithm for 
building custom annotation pipelines and annotating batches of genomes. Sci. Rep. 5:8365. doi: $10.1038 /$ srep08365

Brightwell, G., and Clemens, R. (2012). Development and validation of a realtime PCR assay specific for Clostridium estertheticum and C. estertheticum-like psychrotolerant bacteria. Meat Sci. 92, 697-703. doi: 10.1016/j.meatsci.2012. 06.025

Broda, D. M., Bell, R. G., Boerema, J. A., and Musgrave, D. R. (2002). The abattoir source of culturable psychrophilic Clostridium spp. causing "blown pack" spoilage of vacuum-packed chilled venison. J. Appl. Microbiol. 93, 817-824. doi: $10.1046 / j .1365-2672.2002 .01757 . x$

Broda, D. M., Boerema, J. A., and Brightwell, G. (2009). Sources of psychrophilic and psychrotolerant clostridia causing spoilage of vacuum-packed chilled meats, as determined by PCR amplification procedure. J. Appl. Microbiol. 107, 178-186. doi: 10.1111/j.1365-2672.2009.04193.x

Broda, D. M., Saul, D. J., Lawson, P. A., Bell, R. G., and Musgrave, D. R. (2000). Clostridium gasigenes sp. nov., a psychrophile causing spoilage of vacuumpacked meat. Int. J. Syst. Evol. Microbiol. 50, 107-118. doi: 10.1099/0020771350-1-107

Cañadas, I. C., Groothuis, D., Zygouropoulou, M., Rodrigues, R., and Minton, N. P. (2019). RiboCas: a universal CRISPR-based editing tool for Clostridium. ACS Synth. Biol. 8, 1379-1390. doi: 10.1021/acssynbio.9b00075

Cavill, L., Renteria-Monterrubio, A. L., Helps, C. R., and Corry, J. E. L. (2011). Detection of cold-tolerant clostridia other than Clostridium estertheticum in raw vacuum-packed chill-stored meat. Food Microbiol. 28, 957-963. doi: 10.1016/j. fm.2011.01.003

Chun, J., Oren, A., Ventosa, A., Christensen, H., Arahal, D. R., da Costa, M. S., et al. (2018). Proposed minimal standards for the use of genome data for the taxonomy of prokaryotes. Int. J. Syst. Evol. Microbiol. 68, 461-466. doi: 10.1099/ijsem.0.002516

Cosentino, S., Voldby Larsen, M., Møller Aarestrup, F., and Lund, O. (2013). PathogenFinder - distinguishing friend from foe using bacterial whole genome sequence data. PLoS One 8:e77302. doi: 10.1371/journal.pone.0077302

Dorn-In, S., Schwaiger, K., Springer, C., Barta, L., Ulrich, S., and Gareis, M. (2018). Development of a multiplex qPCR for the species identification of Clostridium estertheticum, C. frigoriphilum, C. bowmanii and C. tagluense-like from blown pack spoilage (BPS) meats and from wild boars. Int. J. Food Microbiol. 286, 162-169. doi: 10.1016/j.ijfoodmicro.2018.08.020

Eitel, Z., Sóki, J., Urbán, E., and Nagy, E. (2013). The prevalence of antibiotic resistance genes in Bacteroides fragilis group strains isolated in different European countries. Anaerobe 21, 43-49. doi: 10.1016/j.anaerobe.2013.03.001

Glaser, P., Frangeul, L., Buchrieser, C., Rusniok, C., Amend, A., Baquero, F., et al. (2001). Comparative genomics of Listeria species. Science 294, 849-852. doi: 10.1126/science. 1063447

Heap, J. T., Pennington, O. J., Cartman, S. T., Carter, G. P., and Minton, N. P. (2007). The ClosTron: a universal gene knock-out system for the genus Clostridium. J. Microbiol. Methods 70, 452-464. doi: 10.1016/j.mimet.2007. 05.021

Henriques, A. O., Beall, B. W., Roland, K., and Moran, C. P. (1995). Characterization of cotJ, a $\sigma(\mathrm{E})$-controlled operon affecting the polypeptide composition of the coat of Bacillus subtilis spores. J. Bacteriol. 177, 3394-3406. doi: 10.1128/jb.177.12.3394-3406.1995

Henriques, A. O., and Moran, C. P. Jr. (2007). Structure, assembly, and function of the spore surface layers. Annu. Rev. Microbiol. 61, 555-588. doi: 10.1146/ annurev.micro.61.080706.093224

Húngaro, H. M., Caturla, M. Y. R., Horita, C. N., Furtado, M. M., and Sant'Ana, A. S. (2016). Blown pack spoilage in vacuum-packaged meat: a review on clostridia as causative agents, sources, detection methods, contributing factors and mitigation strategies. Trends Food Sci. Technol. 52, 123-138. doi: 10.1016/J. TIFS.2016.04.010

Kreiswirth, B. N., Löfdahl, S., Betley, M. J., O'reilly, M., Schlievert, P. M., Bergdoll, M. S., et al. (1983). The toxic shock syndrome exotoxin structural gene is not detectably transmitted by a prophage. Nature 305, 709-712. doi: $10.1038 /$ 305709a0

Kuiper, I., Lagendijk, E. L., Pickford, R., Derrick, J. P., Lamers, G. E. M., Thomas-Oates, J. E., et al. (2004). Characterization of two Pseudomonas putida lipopeptide biosurfactants, putisolvin I and II, which inhibit biofilm formation and break down existing biofilms. Mol. Microbiol. 51, 97-113. doi: 10.1046/j. 1365-2958.2003.03751.x
Lee, I., Chalita, M., Ha, S. M., Na, S. I., Yoon, S. H., and Chun, J. (2017). ContEst16S: an algorithm that identifies contaminated prokaryotic genomes using 16S RNA gene sequences. Int. J. Syst. Evol. Microbiol. 67, 2053-2057. doi: 10.1099/ijsem. 0.001872

Liu, B., Zheng, D., Jin, Q., Chen, L., and Yang, J. (2019). VFDB 2019: a comparative pathogenomic platform with an interactive web interface. Nucl. Acids Res. 47, D687-D692. doi: 10.1093/nar/gky1080

Marchler-Bauer, A., Anderson, J. B., Chitsaz, F., Derbyshire, M. K., DeWeeseScott, C., Fong, J. H., et al. (2009). CDD: specific functional annotation with the conserved domain database. Nucl. Acids Res. 37, D205-D210. doi: 10.1093/ nar/gkn845

Meier-Kolthoff, J. P., Auch, A. F., Klenk, H. P., and Göker, M. (2013). Genome sequence-based species delimitation with confidence intervals and improved distance functions. BMC Bioinform. 14:60. doi: 10.1186/1471-2105$14-60$

Meier-Kolthoff, J. P., Hahnke, R. L., Petersen, J., Scheuner, C., Michael, V., Fiebig, A., et al. (2014). Complete genome sequence of DSM 30083T, the type strain (U5/41T) of Escherichia coli, and a proposal for delineating subspecies in microbial taxonomy. Stand. Genomic Sci. 9:2. doi: 10.1186/1944-3277-9-2

Moschonas, G., and Bolton, D. J. (2013). Characterization of a potentially novel 'blown pack' spoilage bacterium isolated from bovine hide. J. Appl. Microbiol. 114, 771-777. doi: 10.1111/jam.12077

Moschonas, G., Bolton, D. J., McDowell, D. A., and Sheridan, J. J. (2011a). Diversity of culturable psychrophilic and psychrotrophic anaerobic bacteria isolated from beef abattoirs and their environments. Appl. Environ. Microbiol. 77, 4280-4284. doi: 10.1128/AEM.01778-10

Moschonas, G., Bolton, D. J., Sheridan, J. J., and McDowell, D. A. (2011b). The effect of heat shrink treatment and storage temperature on the time of onset of "blown pack" spoilage. Meat Sci. 87, 115-118. doi: 10.1016/j.meatsci.2010. 09.007

Moschonas, G., Bolton, D. J., Sheridan, J. J., and McDowell, D. A. (2009). Isolation and sources of blown pack spoilage clostridia in beef abattoirs. J. Appl. Microbiol. 107, 616-624. doi: 10.1111/j.1365-2672.2009.04229.x

Moschonas, G., Bolton, D. J., Sheridan, J. J., and McDowell, D. A. (2010). The effect of storage temperature and inoculum level on the time of onset of "blown pack" spoilage. J. Appl. Microbiol. 108, 532-539. doi: 10.1111/j.1365-2672.2009. 04455.x

NCBI Resource Coordinators (2018). Database resources of the National Center for Biotechnology Information. Nucl. Acids Res. 46, D8-D13. doi: 10.1093/nar/ gkx1095

Pahalagedara, A. S. N. W., Flint, S., Palmer, J., Brightwell, G., and Gupta, T. B. (2020). Antimicrobial production by strictly anaerobic Clostridium spp. Int. J. Antimicrob. Agents 55:105910. doi: 10.1016/j.ijantimicag.2020.105910

Paredes-Sabja, D., Raju, D., Torres, J. A., and Sarker, M. R. (2008). Role of small, acid-soluble spore proteins in the resistance of Clostridium perfringens spores to chemicals. Int. J. Food Microbiol. 122, 333-335. doi: 10.1016/j.ijfoodmicro. 2007.12.006

Parks, D. H., Imelfort, M., Skennerton, C. T., Hugenholtz, P., and Tyson, G. W. (2015). CheckM: assessing the quality of microbial genomes recovered from isolates, single cells, and metagenomes. Genome Res. 25, 1043-1055. doi: 10. 1101/gr.186072.114

Rajagopal, S., McMullen, L. M., Gill, C. O., and Yang, X. (2016). Characterization of germination of spores of Clostridium estertheticum, the primary causative agent of blown pack spoilage of vacuum packaged beef. Food Res. Int. 87, 109-114. doi: 10.1016/j.foodres.2016.06.032

Raju, D., Setlow, P., and Sarker, M. R. (2007). Antisense-RNA-mediated decreased synthesis of small, acid-soluble spore proteins leads to decreased resistance of Clostridium perfringens spores to moist heat and UV radiation. Appl. Environ. Microbiol. 73, 2048-2053. doi: 10.1128/AEM.02500-06

Reid, R., Burgess, C. M., McCabe, E., Fanning, S., Whyte, P., Kerry, J., et al. (2017). Real-time PCR methods for the detection of blown pack spoilage causing Clostridium species; C. estertheticum, C. gasigenes and C. ruminantium. Meat Sci. 133, 56-60. doi: 10.1016/j.meatsci.2017.06.001

Rossolini, G. M., D’Andrea, M. M., and Mugnaioli, C. (2008). The spread of CTXM-type extended-spectrum $\beta$-lactamases. Clin. Microbiol. Infect. 14, 33-41. doi: 10.1111/j.1469-0691.2007.01867.x

Sebaihia, M., Peck, M. W., Minton, N. P., Thomson, N. R., Holden, M. T. G., Mitchell, W. J., et al. (2007). Genome sequence of a proteolytic (Group 
I) Clostridium botulinum strain Hall $\mathrm{A}$ and comparative analysis of the clostridial genomes. Genome Res. 17, 1082-1092. doi: 10.1101/gr.628 2807

Shimizu, Y., Ogata, H., and Goto, S. (2017). Type III polyketide synthases: functional classification and phylogenomics. ChemBioChem 18, 50-65. doi: 10.1002/cbic. 201600522

Silva, A. R., Paulo, ÉN., Sant'Ana, A. S., Chaves, R. D., and Massaguer, P. R. (2011). Involvement of Clostridium gasigenes and C. algidicarnis in 'blown pack" spoilage of Brazilian vacuum-packed beef'. Int. J. Food Microbiol. 148, 156-163. doi: 10.1016/j.ijfoodmicro.2011.05.016

Tatusova, T., DiCuccio, M., Badretdin, A., Chetvernin, V., Nawrocki, E. P., Zaslavsky, L., et al. (2016). NCBI prokaryotic genome annotation pipeline. $\mathrm{Nucl}$. Acids Res. 44, 6614-6624. doi: 10.1093/nar/gkw569

Voitsekhovskaia, I., Paulus, C., Dahlem, C., Rebets, Y., Nadmid, S., Zapp, J., et al. (2020). Baikalomycins A-C, new aquayamycin-type angucyclines isolated from lake baikal derived streptomyces sp. IB201691-2A. Microorganisms 8:680. doi: 10.3390/microorganisms 8050680

von Neubeck, M., Baur, C., Krewinkel, M., Stoeckel, M., Kranz, B., Stressler, T., et al. (2015). Biodiversity of refrigerated raw milk microbiota and their enzymatic spoilage potential. Int. J. Food Microbiol. 211, 57-65. doi: 10.1016/j.ijfoodmicro. 2015.07.001

Walia, A., Guleria, S., Mehta, P., Chauhan, A., and Parkash, J. (2017). Microbial xylanases and their industrial application in pulp and paper biobleaching: a review. 3 Biotech 7, 1-12. doi: 10.1007/s13205-0160584-6

Wambui, J., Püntener, S., Corti, S., Cernela, N., and Stephan, R. (2020). Detection of psychrophilic Clostridium spp. causing "blown pack" spoilage in meat juice samples from chilled vacuum-packed beef and lamb meat imported from different countries to Switzerland. J. Food Prot. 83, 56-59. doi: 10.4315/0362028X.JFP-19-21

Wambui, J., and Stephan, R. (2019). Relevant aspects of Clostridium estertheticum as a specific spoilage organism of vacuum-packed meat. Microorganisms 7:142. doi: 10.3390/microorganisms7050142

Wambui, J., Tasara, T., Kamau Njage, P. M., and Stephan, R. (2018). Species distribution and antimicrobial profiles of Enterococcus spp. isolates from Kenyan small and medium enterprise slaughterhouses. J. Food Prot. 81, 14451449. doi: 10.4315/0362-028X.JFP-18-130

Yang, X., and Badoni, M. (2013). Substrate utilization during incubation in meat juice medium of psychrotolerant clostridia associated with blown pack spoilage. Food Microbiol. 34, 400-405. doi: 10.1016/j.fm.2013.02.003
Yang, X., Gill, C. O., and Balamurugan, S. (2010). Products of glucose and lactate fermentation, and utilization of amino acids by Clostridium estertheticum subsp. laramiense and estertheticum growing in Meat Juice Medium. J. Food Prot. 73, 1348-1352. doi: 10.4315/0362-028X-73.7.1348

Yang, X., Wang, H., Badoni, M., Youssef, M. K., Gill, C. O., Badoni, M., et al. (2014). Effects of meat $\mathrm{pH}$ on growth of 11 species of psychrotolerant clostridia on vacuum packaged beef and blown pack spoilage of the product. Food Microbiol. 39, 13-18. doi: 10.1016/j.fm.2013.10.008

Yoon, S. H., Ha, S. M., Kwon, S., Lim, J., Kim, Y., Seo, H., et al. (2017a). Introducing EzBioCloud: a taxonomically united database of 16S rRNA gene sequences and whole-genome assemblies. Int. J. Syst. Evol. Microbiol. 67, 1613-1617. doi: 10.1099/ijsem.0.001755

Yoon, S. H., Ha, S. M., Lim, J., Kwon, S., and Chun, J. (2017b). A large-scale evaluation of algorithms to calculate average nucleotide identity. Int. J. Gen. Mol. Microbiol. 110, 1281-1286. doi: 10.1007/s10482-017-0844-4

Yu, Z., Gunn, L., Brennan, E., Reid, R., Wall, P. G., Gaora, P., et al. (2016). Complete genome sequence of Clostridium estertheticum DSM 8809, a microbe identified in spoiled vacuum packed beef. Front. Microbiol. 7:1764. doi: 10.3389/fmicb. 2016.01764

Zankari, E., Hasman, H., Cosentino, S., Vestergaard, M., Rasmussen, S., Lund, O., et al. (2012). Identification of acquired antimicrobial resistance genes. J. Antimicrob. Chemother. 67, 2640-2644. doi: 10.1093/jac/dks261

Zavascki, A. P., Goldani, L. Z., Li, J., and Nation, R. L. (2007). Polymyxin B for the treatment of multidrug-resistant pathogens: a critical review. J. Antimicrob. Chemother. 60, 1206-1215. doi: 10.1093/jac/dkm357

Zhu, S., Zhang, C., Wu, H., Jie, J., Zeng, M., Liu, Z., et al. (2017). Spoilage of refrigerated $\left(4^{\circ} \mathrm{C}\right)$ Litopenaeus vannamei: cooperation between Shewanella species and contribution of cyclo-(L-Pro-L-Leu)-dependent quorum sensing. Int. J. Food Sci. Technol. 52, 1517-1526. doi: 10.1111/ijfs.13427

Conflict of Interest: The authors declare that the research was conducted in the absence of any commercial or financial relationships that could be construed as a potential conflict of interest.

Copyright (c) 2020 Wambui, Cernela, Corti and Stephan. This is an open-access article distributed under the terms of the Creative Commons Attribution License (CC BY). The use, distribution or reproduction in other forums is permitted, provided the original author(s) and the copyright owner(s) are credited and that the original publication in this journal is cited, in accordance with accepted academic practice. No use, distribution or reproduction is permitted which does not comply with these terms. 